\title{
Jerusalém na perspeetiva neotestamentária de Mateus
}

\section{Jerusalem in the neotestamentary perspective of Matthew}

\author{
José Aguiar Nobre* \\ Chaybom Anttone Rufino**
}

Recebido em: 09/06/2020. Aceito em: 08/07/2020.

Resumo: Jerusalém é a cidade da morada de Deus. É o arquétipo de toda cidade, cuja vocação universal à santidade se exterioriza. Isso já é evidente, de forma clara e objetiva pela sua própria história. Cidade que o rei Davi, segundo o coração de Deus, conquistou sem derramar sangue. É a cidade paradigmática em que o próprio Deus quis ser o seu Rei celeste. Contudo, aos poucos os seus interesses de poder vão se obscurecendo ante a grande luz do Salvador. Diante disso, indaga-se: face a uma cultura de morte, como Ihe despertar para captar a Luz da Estrela (Mt 2,1-12)? Metodologicamente, trata-se de uma pesquisa bibliográfica. Cujo objetivo é reforçar que a Jerusalém celeste deve ser o

* Pós-Doutor em Filosofia (Universidade Federal do Paraná, UFPR, Curitiba-PR, 2019). Pós-Doutor em Educação (Pontifícia Universidade Católica de Campinas, PUC-Campinas, Campinas-SP, 2019). Doutorado em andamento em Filosofia (Universidade Federal do Paraná, Curitiba-PR). Doutor em Teologia (Pontifícia Universidade Católica do Rio de Janeiro, PUC-Rio, Rio de Janeiro-RJ, 2017). Mestre em Educação (Pontifícia Universidade Católica de Campinas, PUC Campinas, Campinas-SP, 2011). Graduado em Pedagogia (Claretiano Centro Universitário, Claretiano/BAT, 2019). Graduado em Teologia (Escola de Ensino Superior Fabra, FABRA, Serra-ES, 2018). Licenciado em Filosofia (Centro Universitário Assunção, UNIFAI, São Paulo-SP, (2008). Graduado em Teologia (Pontificium Atheneum S. Anselmi de Urbe, PASAU, Roma, Itália, 2007). Graduado em Filosofia (Pontifícia Universidade Católica de Campinas, PUC-Campinas, Campinas-SP, 2002).

E-mail: nobre.jose@gmail.com

** Mestre em Teologia (Pontifícia Universidade Católica do Paraná, PUC-PR, Curitiba-PR, 2020). Pós-Graduação Lato sensu em Ensino Religioso (MULTIVIX - Nova Venécia-ES, 2013). Especialização em Educação em Direitos Humanos (Neaad-UFES-Serra-ES, 2013). Graduado em Teologia (Pontifícia Universidade Católica de São Paulo, PUC-SP, São Paulo-SP, 2018). Graduado em Filosofia (Pontifícia Universidade Católica de Campinas, PUC-Campinas, Campinas-SP, 2011). Licenciado em Filosofia (Centro de Ensino Superior FABRA, Serra-ES, 2014).

E-mail: chaybom.rufino@gmail.com 
sonho a ser buscado, preservado. Sabe-se que Jerusalém, quando não mais manifestou a sua verdadeira vocação, passou a ser vista como local de morte e oposição ao plano de Deus. Na conjuntura urbana hodierna, percebe-se que há também uma realidade de morte e violências desveladas que precisam ser banidas. A cidade que recebe os profetas enviados, cujas vozes foram silenciadas e as vidas ceifadas que precisa voltar a ser a morada de Deus nos seus filhos todos. Para tanto, os resultados esperados circunscrevem-se à fuga de toda forma de farisaísmo, casuística e legalismos que são sempre desprovidos de misericórdia. Na cidade celeste deverá favorecer a vida digna que brota da prática e regra de justiça inerente ao ser do discipulado. Sabe-se que sem justiça não há paz. Onde imperam os projetos de anti-vida, não há espaço para a verdade do Evangelho. Verdade que reivindicará sempre a sua efetivação.

Palavras-chave: Jerusalém. Santidade. Vocação. Salvador. Vida.

Abstract: Jerusalem is the city of God's abode. It is the archetype of every city, whose universal vocation to holiness is externalized. This is already evident, clearly and objectively from its own history. City that King David, after God's own heart, conquered without shedding blood. It is the paradigmatic city in which God himself wanted to be his heavenly King. However, little by little his interests in power became obscured by the great light of the Savior. In view of this, it is asked: in the face of a culture of death, how can it be awakened to capture the Star Light (Mt 2,1-12)? Methodologically, it is a bibliographic search. The purpose of which is to reinforce that the heavenly Jerusalem must be the dream to be sought, preserved. It is known that Jerusalem, when it no longer manifested its true vocation, came to be seen as a place of death and opposition to God's plan. In today's urban environment, it is clear that there is also a reality of death and unveiled violence that needs to be banned. The city that receives the prophets sent, whose voices have been silenced and lives cut off that need to return to being the abode of God in all their children. Therefore, the expected results are limited to the escape of all forms of self-righteousness, casuistry and legalisms that are always devoid of mercy. In the celestial city, it should favor the dignified life that springs from the practice and rule of justice inherent in the being of discipleship. It is known that without justice there is no peace. Where anti-life projects prevail, there is no room for the truth of the Gospel. A truth that will always claim its effectiveness.

Keywords: Jerusalem. Holiness. Vocation. Savior. Life.

\section{Introdução}

Jerusalém, a cidade que Deus escolheu para sua morada, porém no Evangelho segundo Mateus está longe de se concretizar essa vocação divina. A cidade é vista de maneira negativa dentro da narrativa mateana (um exemplo nas molduras do textual de Mateus - caps 1-2 e caps 26-28). A primeira vez que a cidade é citada (Mt 2,1), ela é apresentada como a cidade que não consegue ver a luz do Salvador. Posteriormente, 
é onde Jesus deveria morrer. O lugar onde o projeto de Deus poderia ser visto com mais clareza é obscurecido justamente pela vaidade e o poder. Local onde as autoridades mudam a verdade da ressurreição para a defesa dos interesses pessoais (Mt 28,11-15). Paradoxalmente, aí é onde não se vê o Ressuscitado. No Evangelho segundo Mateus, a cidade que Deus escolheu para sua morada, não tem a potência de se abrir para ser realmente a morada, sendo esta abandonada por Deus (Mt 23,37-24,1).

Argumenta-se que a dinâmica do Evangelho segundo Mateus abre uma série de chaves de leituras para a atualidade. Uma delas é a vocação das grandes (e também das pequenas) cidades para efetivar a santidade e a concretização do projeto salvífico e universal de construção do Reino. Entende-se que, em face de uma cultura de morte, torna-se um grande despertar a criatura humana para captar hoje a Luz da Estrela (Mt 2,1-12). Acredita-se que o seu brilho resplandece em cada ser que nela habita. Para tanto, se faz necessária a fuga dos projetos de morte impostos pelo poder (Mt 2,13-18). Nesse sentido, para ver o "Bendito que vem em Nome do Senhor" (S1 118,26; Mt 21,9; 23,39), torna-se necessária uma consciência de todos os habitantes da cidade. Consciência de que respeitar a todos não trata-se de uma opção, mas de uma vocação genuinamente humana. Agir, diferentemente, é desvirtuar a vocação da cidade santa. Captar essa verdade de fé e urgência na defesa da vida, para que todos na cidade possam respirar, torna-se uma alternativa eminentemente viva e necessária para a atualidade e a sintonia com o sonho da comunidade mateana.

\section{A Jerusalém: Teologia e História}

O nome da cidade, nasce nos tempos mais remotos. Aparece em textos egípcios de reprovações do médio império e a sua grafia a julgamento de muitos especialistas era rushalimum, no lugar de urušalimum ${ }^{1}$. O nome urushalimum é atestado desde Amenófis IV (1377-1358 a.C.). No Antigo Testamento, tem-se Yerushaláyim (ירושלים). Na Septuaginta,

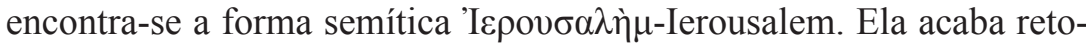

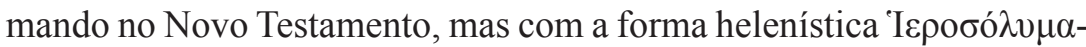
Ierosoluma ${ }^{2}$. Segundo a história, ela aparece 11 vezes em Mateus (Mt

\footnotetext{
Cf. MAZAR. Città di Gerusalemme. In: ROLLA, Armando. et ali. Enciclopedia della Bibbia. Vol. 2. Torino-Leumann: Elle Di Ci, 1970. p. 798.

2 Cf. CARREZ, Jerusalém. In: BROWN, Colin; COENEN, Lothar. Dicionário Internacional de Teologia do Novo Testamento. 2. ed. São Paulo: Editora Nova Vida, 2004. p. 928
} 
$2,1 ; 2,3 ; 3,5 ; 4,25 ; 5,35 ; 15,1 ; 16,21 ; 20,17 ; 20,18 ; 21,1 ; 21,10)$. No Evangelho segundo Mateus, a única vez que aparece a forma semítica

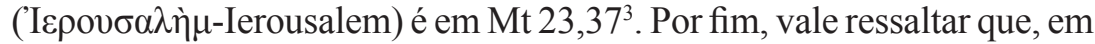
todo o restante do texto mateano, é utilizada a forma helenizada ${ }^{4}$. Tendo visto esse pequeno registro histórico, observe a sua teologia.

\subsection{Teologia sobre Jerusalém}

Como se sabe, Jerusalém tem uma grande importância no judaísmo. É nela, testemunhada a sua presença e relevância, seja na Bíblia hebraica, seja nas fontes apócrifas de Qumran ${ }^{5}$. Situada por cima do monte, em uma região sem agricultura nem manufaturas, Jerusalém deve a sua expansão à vontade do Rei Davi e à sua vocação de cidade santa. Seria uma contradição para geólogos e economistas, se não se considerasse a multidão de peregrinos que se encaminhavam à cidade por seus mais de trinta séculos. Argumenta-se que o fenômeno das peregrinações a Jerusalém não tem par, ao menos no que diz respeito à duração, no mundo. E quando a cidade perdeu a sua importância política, depois do exílio, ainda se viu acorrer a ela homens de todas as nações ${ }^{6}$. Como ainda hoje acontece, e continua sendo uma experiência ímpar na vida de qualquer pessoa que pisa naquele solo fértil de experiências mistéricas. Pois ao contemplar a sua geografia, ou mesmo ouvir os agradáveis sons de seus templos, já marcam não somente a memória, como o interior de seus peregrinos. Isso, inevitavelmente é dito à luz da fé, da crença, da confiança e esperança em Deus. Uma vez que, como o próprio subtítulo enuncia, trata-se de uma teologia sobre Jerusalém e da soteriologia.

Abrangendo uma visão panorâmica da história da salvação, se pode ver na Antiga Aliança uma saída para a Jerusalém: quando Abraão, pai da fé, saiu de Ur dos Caldeus, quando o povo que era escravo no Egito saiu rumo à Terra Prometida, ou mesmo o retorno da Babilônia, depois do cativeiro. Há uma saída de todas as partes da Palestina e depois, mais tarde, todos os prosélitos. Esse movimento de peregrinações se conclui

3 Cf. BIBLEWORKS project for BibleWorks 10. Versão 10.0.8.755: BibleWorks Copyright, 2017.

4 Cf. MICHELINI, Giulio. Matteo: Introduzione, traduzione e comento. Torino: Edizioni San Paolo, 2013. p. 376

5 Cf. MICHELINI, 2013. p. 376.

6 Cf. RAMLOT, Teologia sul Gerusalemme. In: ROLLA, Armando. et ali. Enciclopedia della Bibbia. Vol. 2. Torino-Leumann: Elle Di Ci, 1970. p 873. 
ou culmina no dia de Pentecostes, onde tudo o que foi convergido a Jerusalém encontra a sua unidade. A partir daí, se inicia o tempo da Igreja. Esta, deverá, por vocação estar aberta incondicionalmente aos gentios de todos os tempos. A partir daí torna-se um movimento de saída e de expansão universal, que realiza aquilo que Jesus havia preanunciado para a história da salvação: "sereis minhas testemunhas em Jerusalém em toda a Judeia e na Samaria, até os confins da terra" (At 1,8). Visto este breve itinerário, argumenta-se que nenhum integrante da Igreja, para ser fiel ao Espírito de Deus, jamais deverá pôr fim à vocação da cidade santa, presente em cada comunidade que tece e compõe a riqueza das cidades que rumam à Jerusalém Celeste. Entende-se que somente assim, a grande visão da Jerusalém Celeste (Ap 21) será verdadeiramente alcançada. Em se pensando e agindo assim todos os seres das várias cidades espalhadas pelo cosmo, é que se conclui a visão cristã da Jerusalém futura ${ }^{7}$.

\subsection{A cidade de Davi $(2 \mathrm{Sm} 5,7)$}

A conquista de Jerusalém responde a uma intenção formal de Davi que, até então, os judaítas não haviam podido adquirir, de forma definitiva, tomar posse daquela cidade fortificada, apesar de certos episódios favoráveis (Js 10,1-23; 12,10; Jt 1,4-8). A cidade que se acreditava inexpugnável, veio a ser tomada com a astúcia de Davi e recebe o nome de "cidade de Davi" (2Sm 5,6-9). Todavia, foi o antigo nome urušalim que prevaleceu. Os relatos bíblicos não são claros quanto à conquista de Jerusalém. Uma cidade que antes tivera uma importância secundária em Canaã, entrou para o âmbito da tradição que, por fim, resultaria no monoteísmo histórico. Ela se tornou um dos lugares mais sagrados e, portanto, mais disputados do mundo. Certamente, quando David tomou Jerusalém deve ter sentido um duplo alívio, pois capturou o enclave jebuseu situado no centro do seu reino unido e aí encontrou uma capital mais adequada ${ }^{8}$. De fato, a cidade não pertencia nem às tribos do sul, que haviam escolhido Davi como rei, nem às tribos do norte. Sabe-se que foi necessário unificar de forma definitiva todas as tribos sob uma única monarquia 9 .

$7 \quad$ Cf. RAMLOT, 1970, p. 873-874.

8 Cf. ARMSTRONG, Karen. Jerusalém: uma cidade, três religiões. São Paulo: Companhia das letras, 1996. p. 61-62.

9 Cf. RAMLOT, 1970, p. 874-875. 
Os textos bíblicos dão a entender que sua situação política era excelente, devido à sua localização quase no centro da Palestina. Subindo sobre a parte mais alta desta cadeia, circundada por depressões, se encontra em uma posição estratégica e excepcional. Tanto é assim, que os cercos de Jerusalém são lembrados entre os mais memoráveis de toda a história militar ${ }^{10}$. Entende-se que foi uma pura intuição cheia de bons resultados a decisão de Davi de transportar para a cidade, a Arca da aliança. Além do mais, o resultado foi tão animador que o rei se esmerou para construir um altar ( $2 \mathrm{Sm} 6,12 ; 24-25)$. Nesse sentido, ele foi capaz de projetar a construção do Templo, que deveria assegurar a Jerusalém a sucessão na importância do povo. Mediante isso, aquele santuário que era exercido até então a sua posição central pela antiga Shilo (Silo) uma primazia, foi para Jerusalém o ápice da importância o novo Santuário das tribos. Somente do lado econômico a cidade apresentava aspectos negativos, pois, estava situada em uma região de poucos recursos naturais e longe de grandes vias de comunicação não poderia aspirar se tornar um grande centro de tráfego internacional, pelo contrário, o seu destino era um outro ${ }^{11}$.

Outrossim, com o sacerdócio de Jerusalém, confiado por Salomão a Sadoc e aos seus filhos, se pode reivindicar uma grande antiguidade para o santuário. Uma tradição conservava a recordação de um encontro entre Abraão, o pai da fé, e Melquisedec, rei sacerdote de Salém (provavelmente a forma abreviada de Jerusalém: S1 76,3; Midrash do Gênesis, 22,13). Logo em seguida, Melquisedec apresenta a Abrão uma oferta de pão e vinho e o abençoa. Por sua vez, Abrão "lhe dá a décima parte de tudo" (Gn 14,17-20) $)^{12}$. Sabe-se que o altar, e, posteriormente, o Templo foram construídos sobre a eira de Areúna, indicado pelo profeta $\mathrm{Gad}$ ( $2 \mathrm{Sm}$ 24,18-19). Reis, sacerdotes e profetas contribuíram para a importância de Jerusalém, que na tradição antiga, não era objeto de nenhuma promessa, antes, era uma "cidade de estrangeiros" (Jz 19,11-12), que se evitava ${ }^{13}$.

Nesse sentido, vê-se que Jerusalém não tinha nenhum significado na tradição fundamental da constituição tribal. Além do mais, ela tinha,

\footnotetext{
10 Cf. RAMLOT, 1970, p. 875.

11 Cf. RAMLOT, 1970, p. 875.

12 Cf. CLIFFORD; MURPHY. Gênesis. In: BROWN, Raymond E.; FITMEYER, Joseph A.; MURPHY, Roland E. Novo comentário Bíblico São Jerônimo-AntigoTestamento. São Paulo: Paulus, 2007. p. 83-84.

13 Cf. RAMLOT, 1970, p. 876.
} 
antes do exílio, uma rival mais próspera na Samaria e foi apenas tocada na profecia messiânica. Todavia, já era vista como "morada de YHWH" e, pouco antes do exílio, pessoas da Samaria com homens de Silo e de Siquém iam a Jerusalém para apresentar ofertas no Templo ( Jr 41,5). Iniciava-se assim, a verdadeira glória de Jerusalém, que não consistia ainda no seu papel como capital, mas no fato de ser um lugar onde surgiu o Templo ${ }^{14}$. Além de cidade de Davi, aos poucos Jerusalém recebe mais um atributo: Jerusalém se torna a morada de YHWH (S1 76,3), a cidade de Deus (S1 46,5), o lugar onde é invocado o nome de YHWH dos exércitos (Is 18,7; 8,18), o lugar onde Deus faz ouvir a sua voz (Am 1,2).

Em Isaías, Jerusalém adquire uma importância toda especial, pois é o lugar da manifestação de YHWH (Is 6), e o monte de Sião é frequentemente recordado pelo profeta (29 vezes em Is $1-39$ e por 17 vezes em Is 40-66). É o lugar de reunião de todos os povos (Is 2) e a cidade, ao qual, mesmo os etíopes levam as suas ofertas (Is 18,1-7). A cidade fundada por YHWH (Is 14,32), fortificada pela proteção divina (Is 10,24; 31,45), cidade de refúgio (Is 14,32) e de peregrinações alegres (Is 30,29). Como o novo Sinai, torna-se assim, a cidade na qual YHWH tem o seu fogo e o seu forno (Is 31,9). Onde YHWH pausará as tropas Assírias e as pisará sobre os montes (Is 14,25). Se bem que, na região, poderia comparar Jerusalém a um sacramento de Deus, em Isaías, essa mística da cidade santa, não tem nenhum paládio. Tão pouco a presença divina necessária, exclusiva e definitiva, exibia nada que se assemelhasse a uma mágica inviolabilidade ${ }^{15}$. Essa predileção não exclui absolutamente as censuras e reprovações divinas (Is 3,8; 10,12. Ressalta que, "com tudo isso não se acalmou a sua ira, e sua mão continuou estendida" (Is 5,25 contra a Samaria Is $9,11.16 .20 ; 10,4)$.

A cidade do Messias, "o meu santo monte" (Is 11,9), será purificada pela ação divina e se tornará uma cidade justa e uma cidade fiel (Is 1,26) salva sob Acaz (Is 7,8) e sob Ezequias (2Rs 18,17-19.37). Cidade onde se concretiza a unidade (S1 122), e o propósito de todo o programa da reforma deuteronomista (Dt 16,1-8; 2Rs 22-23). É a cidade onde YHWH põe o seu nome (2Rs 21,4; Is 31,9; J1 4,17; 2Cr 33,4; S1 132,13). Os historiógrafos deuteronomistas exaltaram a eleição de Jerusalém (1Rs 11,1.32.36; 2Rs 23,37), por ser a cidade amada por Deus (S1 78,68; 87,2; Zc 1,14; Ecl 24,11; Ap 20,9) e o monte do Templo (Mq 3,12; Ag 1,8;

\footnotetext{
14 Cf. RAMLOT, 1970, p. 877.

15 Cf. RAMLOT, 1970, p. 877-878.
} 
$1 \mathrm{Mc} 4,46.48 ; 7,35.37 ; 10,41)$. Em tudo que se pode ver, no ideal acima para qualquer cidade, torna-se um desafio constante para todas elas, em todos os tempos e lugares.

Argumenta-se que não obstante a isso, já no tempo de Isaías, o profeta Miqueias havia anunciado a ruína da cidade por sua injustiça realizada, edificando as construções com sangue e com impiedade (Mq 3,9-12). A missão de Jeremias é de reprovar a apostasia de Jerusalém ( $\mathrm{Jr}$ $2,1-25 ; 11,13 ; 26,16)$, fazendo o apelo/convite de purificação $(\operatorname{Jr} 4,14)$ e se vê obrigado a anunciar a sua ruína $(\mathrm{Jr} 9,10 ; 13,9)$. O exemplo de Silo demonstra que YHWH é capaz de realizar a sua ameaça, mesmo contrário à doce ilusão e laxismo do povo $(\mathrm{Jr} 7,12 ; 26,6)$. Para Jeremias a cidade é ameaçada pelos inimigos do norte $(\mathrm{Jr} 1,15 ; 4,5 ; 6,1.8)$, por meio de um gesto simbólico, a jarra quebrada, anuncia a sua destruição $(\operatorname{Jr} 19,11)$, e efetivamente esta é devastada (Jr 38,28; 39,8; 44,2). Porém, continua sendo ela a cidade $(\operatorname{Jr} 51,50)$ da qual se deve conservar a recordação ${ }^{16}$.

Jeremias não fala movido por um ressentimento pessoal contra a cidade de Jerusalém, ele anuncia a sua restauração (Jr 33,10-11; 30,18; $31,38)$ e o grande retorno a Sião (Jr 31,6), predizendo que depois do exílio não será mais necessário construir uma Arca da Aliança, pois, a Nova Jerusalém será ela mesma o trono de YHWH (Jr 3,17; Ex 25,10; $2 \mathrm{Sm} 6,7)$, assim como era a Arca ${ }^{17}$.

Enfim, com Ezequiel, que ignora o tema de Sião, se tem o anúncio da ruína de Jerusalém (Ez 4,5; 24,1-14) por meio de gestos simbólicos. O profeta tem a visão dos pecados de Jerusalém (Ez 8; 11,1-13) a cidade sanguinária (Ez 22,1-30) e do seu castigo (Ez 9-10) e a glória de YHWH que abandona a cidade de Jerusalém (Ez 11,23). Contudo, nenhum outro anunciou com tanto fervor o renascimento da cidade de Jerusalém (Ez 40-48), cujo destino é indicado por um novo nome: "YHWH está lá" (Ez 48,35).

\subsection{A cidade do grande Rei}

Com a destruição do Templo em 586 a.C., a deportação e o exílio na Babilônia, Jerusalém perde o seu status de capital monárquica, assim como a dinastia davídica deixa de reinar. No livro das Lamentações

16 Cf. RAMLOT, 1970, p. 879.

17 Cf. RAMLOT, 1970, p. 879. 
aparece assim: "nossa herança passou a estrangeiros, nossas casas a desconhecidos" (Lm 5,2). Jerusalém se torna algo fantástico (Is 52,1) no imaginário do povo, uma cidade dos sonhos, uma visão que exalta e supera toda dificuldade. Um local onde converge a esperança de Israel ${ }^{18}$.

Na narrativa mateana Jerusalém é a cidade santa (Is 52,1; Dn 9,24; Mt 4,5), os profetas a veem mais gloriosa que antes, porém, com uma vocação puramente religiosa ${ }^{19}$. Todo o período do exílio foi uma espera do momento em que a glória de YHWH retornaria no seu Templo, e se aguarda tal momento para se tributar a Deus, na cidade, um culto perfeito, na qual não estará presente nenhum incircunciso ou impuro (Is 52,1 ) e para realizar o programa do reinado pleno de Deus (Is 52,7), para a redenção de Jerusalém (Is 52,9). E enquanto todas as nações veem a salvação operada por YHWH (Is 52,10), Isaías anuncia a ruína da Babilônia (Is 47; 42,14-15) ${ }^{20}$.

Se o autor do II Isaías, o livro da consolação de Israel (Is 40-55), anunciava somente uma libertação de Jerusalém, os seus discípulos fazem da metrópole religiosa uma luz do mundo (Is 60,1-3.19-20), um lugar de reunião das nações (Is 60,5-10.16; 66,18-19; Mq 4,1-2; Zc 8,20-23; Tb 13,9-11), uma casa de oração para todos os povos (Is 56,7). A cidade recebe novos nomes: minha complacência, Cidade de YHWH, Sião do Santo de Israel (Is 60,14). Desse modo, Jerusalém se torna a capital de uma Terra Santa (Zc 2,17), a esposa de Deus (Is 62, 3-5), objeto de uma nova eleição (Zc 2,16). Essa cidade divina adquiriu a importância e a característica do Reino escatológico ${ }^{21}$. Será como um novo Jardim em Éden (Is 51,3), todas as riquezas do mundo a ela afluirão (Is 60-62), um novo Templo será fundado sobre o alto do monte (Ez 40,2; S1 87,1; Is 2,2; S1 48,3). Jerusalém passa a ser vista como o centro do mundo (Ez $5,5 ; 38,12)$, a cidade para qual é necessário voltar-se para as orações (1Rs 8,38; Dn 6,11), o lugar da habitação de Deus (Eclo 36,18) onde ele escolheu permanecer e retornar ${ }^{22}$.

A restauração de Jerusalém é uma das surpresas da história, uma das mais nobres obstinações de Israel, que deportada, manteve a recordação da cidade santa: "se eu me esquecer de ti, Jerusalém, que me

\footnotetext{
18 Cf. RAMLOT, 1970, p. 880.

19 Cf. MICHELINI, 2013, p. 377.

20 Cf. RAMLOT, 1970, p. 881.

21 Cf. RAMLOT, 1970, p. 881.

22 Cf. RAMLOT, 1970, p. 882.
} 
seque a mão direita! Que se cole a minha língua ao céu da boca caso não lembre de ti, caso eu não eleve Jerusalém ao topo da minha alegria" (S1 137,5-6). Tal foi o conselho/ordem que Jeremias dá os exilados (Jr 51,50). Em face a tudo isso, o decreto de liberdade de Ciro (Esd 1,1-4), rei da Pérsia, permitiu o retornode quarenta e dois mil judeus com o chefe Zorobabel. Traziam consigo os vasos sagrados (Esd 1,5-11) restauraram o altar dos holocaustos e sacrifícios (Esd 3,1-6), mas o novo Templo estava bem distante de ter o mesmo esplendor do primeiro (Esd 3,7-11) e foi reconstruído com grande dificuldade material ${ }^{23}$. Todavia a sua glória deveria ser maior e superar à do antigo Templo $(\mathrm{Ag} 2,9)$.

Mais tarde Neemias obtêm a autorização para reconstruir as muralhas de Jerusalém, cumprindo a sua tarefa com toda pressa, em meio à hostilidade entre os vizinhos $(\mathrm{Ne} 4)$. A cidade foi reconstruída $\mathrm{e}$ repovoada com muitas dificuldades (Ne 7; 11,1-2), todavia, foi possível renovar a aliança na festa solene dos Tabernáculos (Ne 8-10). Durante a época macabaica, Jerusalém e o seu Templo foram os objetos principais da resistência, sendo que o segundo livro dos Macabeus circula em torno desses dois grandes pólos ${ }^{24}$. O livro inicia com a tentativa falida de pilhagem ao Templo e termina com o insucesso de Nicanor contra o Templo, e cada uma das duas partes do livro terminam com uma festa: a da Dedicação (Hanukkarah) (cf. 2Mc 10,7-9) e o relato da morte de Nicanor (2Mc 15). O Templo de Jerusalém é venerado em todo universo $(2 \mathrm{Mc} 2,22 ; 3,12)$ e é o mais santo de toda terra $(2 \mathrm{Mc} 5,15)$ o lugar eleito do Senhor e motivo do seu povo $(2 \mathrm{Mc} 5,19)$. Jesus posteriormente chamará Jerusalém com o título de glória: "a cidade do grande Rei” (Mt $5,35)$, pela qual é proibido fazer juramentos ${ }^{25}$.

\subsection{A cidade que mata os profetas}

Jerusalém é também a cidade que mata os profetas e apedreja os que são enviados. A última afirmação, sem sombra de dúvida, relembra o histórico da cidade e do Templo ${ }^{26}$.

No lugar de refutar o Templo e Jerusalém com desprezo, como os essênios, Jesus sai para visitá-la, porque vem para estar na casa do seu

\footnotetext{
23 Cf. RAMLOT, 1970, p. 883.

24 Cf. RAMLOT, 1970 , p. 883.

25 Cf. RAMLOT, 1970, p. 884.

26 Cf. MICHELINI, 2013, p. 377.
} 
Pai $($ Lc 2,49). Entre os sinóticos, especificamente em Lucas e Mateus, aparecem o juízo sobre Jerusalém (Mt 23,37-39; Lc 13,34-35). Lucas concede um lugar privilegiado a Jerusalém: o seu Evangelho inicia no Templo de Jerusalém e termina no Templo e sabe-se que ele reuniu os episódios da vida de Jesus sobre o signo da subida a Jerusalém (Lc 9,51$18,14)$. No tempo do nascimento de Jesus, um pequeno grupo esperava "a redenção de Jerusalém" (Lc 2,38), quando ele é apresentado no Templo (Lc 2,22) e na transfiguração se fala da morte, e que Ele deveria subir para Jerusalém (Lc 9,31) seu destino final, pois um profeta não pode perecer fora de Jerusalém (Lc 13,33). Jesus sobe com os Doze a Jerusalém para que se cumpra tudo aquilo que está escrito nos profetas sobre o Filho do Homem (Lc 18,31). Essa subida, é por si, aquela subida do povo de Deus que está representada pelos Doze ${ }^{27}$.

Mateus evidencia a próxima queda de Jerusalém (no ano 70), antecipação do fim do mundo (Mt 24; Mc 13; Lc 21,20-36). E esse fim de Jerusalém vem descrito com algumas características do Dia de YHWH anunciado pelos profetas. Apesar de Deus ter visitado Jerusalém com o seu Messias (Mt 21,1), a cidade não aceitou o "mensageiro da paz", e não o reconheceu no tempo do qual era visitada (Lc 19,41-44). Jesus lamenta e chora sobre a cidade (Mt 23,37; Lc 19,41), que será destruída (Lc 19,44).

Na narrativa joanina, Jesus sobe a Jerusalém durante a festa (Jo 5,1; 7,1-14), e ali opera sinais de Deus (Jo 2,23; 3,3; 4,45; 5,1-9; 9), ensina (Jo 5,17-47; 7,14-53; 8-10; 12-17) e realiza o seu ingresso triunfal (Jo 12,12-13). Podemos nos perguntar se por acaso, Jesus não se coloca no lugar de Jerusalém, dado que ele vem reconhecido como "luz das nações" (Lc 2,32; Jo 8,12; 9,5; 12,46) título que anteriormente era conferido somente à cidade de Jerusalém (Is 60,3). Com a vinda do Espírito Santo (Jo 20,19-23) e Pentecostes (At 2,1-13) é realizada a Igreja teocrática universal e, com essa, a antítese do drama da confusão das línguas na Babilônia (Segundo Schwantes ${ }^{28}$, pode-se notar como o exílio ficou muito marcado no povo de Israel, de tal forma que há no livro do Gênesis um relato sobre a confusão das línguas em Gn 11,1-9) e o cumprimento das promessas universalistas com a efusão de uma parte do Espírito Santo e com a reunião, mais uma vez, das nações em Jerusalém. A lista das

27 Cf. RAMLOT, 1970, p. 886.

28 Cf. SCHWANTES, Milton. Projetos de Esperança: Meditacão sobre Gênesis 1-11. São Paulo: Paulinas, 2009. p. 89-101. 
nações, que teriam sido originalmente uma lista dos principais distritos da diáspora judaica, representa a subida dos dispersos para Jerusalém ${ }^{29}$.

Jerusalém é o primeiro centro onde se realiza a missão e a paz cristã, o culto perfeito anunciado para o "o dia da Assembleia" (Dt 18,$16 ; 4,10 ; 9,10$ ). Essa representa o resto dos regenerados (At 2,121.39; Jl 3,1-5), comunidade que vive sob o impulso do Espírito Santo (At 2,1-21.33.38), celebra o Senhor (At 2,47; 3,8.9; 4,4) e proclama suas maravilhas (At 2,11$)$ com felicidade ( $\alpha \gamma \alpha \lambda \lambda i \alpha \sigma ı)$ vive uma paz paradisíaca (At 2,46; 4,32-35). Essa Igreja exercerá mais o seu fascínio em Paulo (At 20,16.22; 21,4.13), que vai perceber a nova Lei que deverá levar às nações (At 9,26-27). E, aqui trará as riquezas coletadas entre a comunidade dos gentios (Rm 15,25-31). Entende-se que nesse processo de narração do fascínio da grandeza do mistério divino que Paulo testemunha está o grande desafio para todos os tempos e lugares, para todas as comunidades de fé. Agindo com a alegria do Evangelho, possibilitará que os habitantes das cidades possam contemplar a Luz da Estrela e fazerem acontecer a instauração do Reino.

Uma vez que se sabe que o lugar onde Deus escolheu por sua morada se tornou um antro de assassinos violentos e sempre dispostos a eliminar os profetas e enviados para chamá-los à conversão, porém são rejeitados ${ }^{30}$. Jerusalém e o seu Templo não são mais o centro da salvação: a realização da Igreja-Mãe é de dar a vida e assumir as dimensões do Reino, que por sua Cabeça (o Cristo), já participa das grandezas celestes ${ }^{31}$ (A Jerusalém de cima, aquela da promessa, "a Cidade do Deus vivo" a "Jerusalém celeste" já é um "encontro festivo" ( $\pi \alpha v \eta \gamma u ̉ \rho \varepsilon \imath)(\mathrm{Hb} 12,22)$ com milhares de anjos: tal é a perfeição da Nova Aliança ${ }^{32}$. Enquanto assistíamos a derrota da Babilônia, o Apocalipse nos apresenta a vitória definitiva de Jerusalém: A Jerusalém escatológica, pronta como uma esposa adornada para o esposo, "descendo dos céus, de junto de Deus" (Ap 21,2), e as nações virão não para lhe trazer riquezas, mas para trazer os seus tributos (Ap 21,24-26). Nesta Nova Jerusalém, Deus fonte de vida e de luz (Ap 21,23) será plenamente acessível sem a necessidade

29 Cf. RAMLOT, 1970, p. 887.

30 Cf. VITÓRIO, Jaldemir. Lendo o Evangelho segundo Mateus: O caminho do discipulado do Reino. São Paulo: Paulus, 2019. p. 255.

31 Cf. RAMLOT, 1970, p. 888.

32 Cf. RAMLOT, 1970, p. 889. 
de mediação de um sacerdócio, e os eleitos poderão ver a sua face (Ap $22,4)$ e poderão dispor dos frutos da árvore da vida $($ Ap 22,14).

\subsection{Dados históricos no tempo de Jesus}

São poucos os dados evangélicos que se tem sobre Jerusalém dos últimos anos de Herodes e dos primeiros anos do Reino de Arquelau (Mt 2,1-12.19-22; Lc 1,5-23; 2,22-38). Este último havia sufocado um tumulto no Templo. Enquanto Arquelau se encontrava em Roma, na ocasião da festa de Pentecostes surgiu uma rebelião contra os oficiais romanos que governavam a cidade; como resultado as arcadas do Templo foram queimadas e a máxima autoridade de província da Síria teve de intervir ${ }^{33}$. Arquelau foi deposto, Jerusalém foi administrada por um procurador romano (6 d.C), o qual residia em Cesareia Marítima e não na cidade Santa de Jerusalém, onde comandava um oficial com tropas estacionadas na fortaleza de Antônia e no palácio herodiano, lugar que servia como praetorium quando os procuradores se transferiram para Jerusalém ${ }^{34}$.

Pôncio Pilatos, durante uma visita à cidade, introduziu a imagem do imperador, mas teve que se retirar às pressas diante do povo enfurecido. O mesmo procurador fez construir o aqueduto superior (o inferior se deve a Herodes): os príncipes da família herodiana primavam pelo gosto de construir; outros foram levados a imitá-los. Sob seu domínio e no período que se seguiu, a indústria de construção teve grande expansão em Jerusalém ${ }^{35}$, que transportava água à cidade das vizinhanças de Belém, e para executar esse trabalho ele usou fundos do tesouro do Templo. Este emprego do dinheiro sagrado repercutiu ainda mais com o descontentamento dos cidadãos de Jerusalém.

A expulsão dos vendedores do Templo e o diálogo com Nicodemos aconteceram durante a páscoa (Jo 2,13-3,21), a cura do paralítico na piscina de Betesda em uma festa não especificada (Jo 5). Betesda, lugar onde aconteceu o milagre, se encontra junto à porta das ovelhas, a norte do Templo. Jesus foi na cidade durante a festa dos Tabernáculos (Jo 7-8), a cura do cego de nascença depois que esse foi lavado na piscina

33 Cf. PIMENTEL. Città di Gerusalemme (história). In: ROLLA, Armando. et ali. Enciclopedia della Bibbia. Vol. 2. Torino-Leumann: Elle Di Ci, 1970. p. 839.

34 Cf. PIMENTEL, 1970, p. 839.

35 Cf. JEREMIAS, J. Jerusalém no Tempo de Jesus. São Paulo: Paulinas,1963. p. 19. 
de Siloé, que seria próximo à saída do túnel de Ezequias (Jo 6). Lucas fala da torre de Siloé que cai $(\operatorname{Lc} 13,4)$ e mata várias pessoas ${ }^{36}$.

No início da Paixão, Jesus se encontra a meio caminho da encosta ocidental do Monte das Oliveiras e chora sobre Jerusalém (Lc 19,37.41-44), hoje o lugar é indicado pela capela Dominus Flevit ${ }^{37}$. Na narrativa evangélica, Jerusalém é antes de tudo o lugar da paixão, morte ressurreição de Jesus Cristo. Pela entrada final em Jerusalém (Mt 21,5; Jo 12,15), Jesus realiza a profecia de Zc 9,9: o nome simbólico e profético "Filha de Sião" é resgatado. Em Mateus, quando Jesus morre, a cidade rebelde se torna a "cidade santa" (Mt 27,53), na qual os eleitos ressuscitados, por um tempo, aparecem a um grande número de pessoas ${ }^{38}$. Depois de ter atravessado o Cedrom, Jesus entrou na cidade e no Templo (Mc 11,11) e os discípulos se admiraram (Mc 13,1) por suas pedras bem trabalhadas $^{39}$. Na atual conjuntura eclesial, argumenta-se que fazer dos fiéis cristãos pedras bem trabalhadas constitui um grande desafio com as peripécias da história hodierna. Contudo, como é próprio da vocação cristã, a contemplação da Luz que brota da Estrela possibilitará enxergar esse horizonte na vida dos Filhos de Deus. Desse modo, ao se dedicar a escrever sobre a Palavra de Deus que ilumina os povos, tendo a cidade santa como paradigma de fala, se entende que é tarefa dos seguidores de Jesus, o trilhar de um caminho que tenha sempre em desejo fazer da sua comunidade de fé um lugar privilegiado da contemplação da santidade de Deus dispensada indistintamente a todos. Desse modo, a história da salvação segue o seu curso no processo sinuoso de construção do Reino.

\subsection{Dados da época dos apóstolos à destruição}

Os fatos narrados nos primeiros dois capítulos do livro dos Atos dos Apóstolos: a eleição de Matias e a descida do Espírito Santo, aconteceram em um local indeterminado (em Lucas se pode fazer uma alusão ao lugar onde foi celebrada a Ceia (Lc 22,12) "o andar superior onde costumavam ficar" (At 1,12$)$ "reunidos no mesmo lugar" $(2,1)$; "a casa de Maria, mãe de João Marcos" $(12,12)$. Parece que é sempre o mesmo lugar, (no andar superior). De modo diferente, vários outros fatos que

\footnotetext{
36 Cf. PIMENTEL, 1970, p. 839-840.

37 Cf. PIMENTEL, 1970, p. 840.

Cf. CARREZ, Jerusalém. In: BROWN, Colin; COENEN, Lothar. Dicionário Internacional de Teologia do Novo Testamento. 2. ed. São Paulo: Editora Nova Vida, 2004. p. 929.

39 Cf. PIMENTEL, 1970, p. 840.
} 
são narrados nos capítulos seguintes ocorreram no Templo (At 4,23-31; $5,12-28 ; 6,9 \mathrm{ss})$. E também se sabe que a condenação e o apedrejamento de Estêvão $($ At 7,58$)$ foram realizados fora dos muros ${ }^{40}$.

A conduta imprudente de Pôncio Pilatos é destacada na sua relação com os judeus, o que acabou causando, no final, a sua destruição. Vitélio, enviado de Roma à Síria, foi a Jerusalém durante a Páscoa e restituiu aos sacerdotes as vestes e outros objetos que eram usados nas festas religiosas ${ }^{41}$. Petrônio, escritor romano, soube compreender os judeus, contudo Calígula se obstinou no propósito de erigir uma estátua sua no Templo de Jerusalém. A intervenção do procurador e de Herodes Agripa evitou uma insurreição em Jerusalém e a situação melhorou depois da morte de Calígula ${ }^{42}$.

A popularidade de Agripa, surgiu por causa da generosidade evidenciada para com o Templo. Foi devida também, em parte, ao rigor que demonstrava contra os cristãos que culminou na morte de Tiago, irmão de João, e com o encarceramento de Pedro (At 12,1-5). O rei favoreceu a expansão da cidade na área externa ao muro, sobre a quarta colina, $\mathrm{e}$ começou a edificar um muro para proteger o novo bairro. Contudo, interrompeu os trabalhos por medo de que o imperador romano suspeitasse de um projeto para uma rebelião ${ }^{43}$. Escavações colocaram em evidência vários traços de um antigo muro mais ao norte de Jerusalém. Sua identificação com o "muro de Agripa" não corresponde, contudo, aos dados de Flávio Josefo, segundo o qual, o muro começava na torre de Hípicos, estendia-se do lado do vento norte até a torre Psefina ${ }^{44}$.

Enquanto as condições de governo na Palestina se tornavam mais difíceis, Claudio concede a Agripa II, Filho de Herodes Agripa, a autoridade para nomear os sumos sacerdotes (49-50 d.C.) e o palácio dos Asmoneus para Jerusalém. Félix, que foi sucessor de Pôncio Festo, um dos procuradores romanos (52-60 d.C), casou-se com uma das irmãs de Agripa e se mostrou hostil aos Judeus, especialmente contra os Zelotas que foram duramente perseguidos. Este mesmo período, foi o que Paulo estava prestes a ser morto pela multidão (At 21,27-30) que estava

\footnotetext{
40 Cf. PIMENTEL, 1970, p. 840.

41 Cf. PIMENTEL, 1970, p. 840

42 Cf. PIMENTEL, 1970, p. 840.

43 Cf. PIMENTEL, 1970, p. 840-843.

44 Cf. PIMENTEL, 1970, p. 843.
} 
agitada $^{45}$. Agripa fez construir no palácio dos Asmoneus, de frente para o Templo, uma varanda com vista para o santuário, mas os chefes dos judeus erigiram uma parede bem alta a oeste do átrio interno, que tirava de Agripa a sua cômoda visão. Festo não conseguiu desmantelá-la ${ }^{46}$.

Albino e Géssio Floro foram péssimos procuradores; o segundo foi o último de todos, tanto pelo tempo, como pela dignidade humana. Se estabeleceu no Palácio, talvez de Herodes o Grande, e se opôs aos judeus com todo tipo de arbitrariedade e abusos. Flávio Josefo garante que num só dia, Géssio, ordenou executar mais de três mil e seiscentos (3.600) homens, mulheres e crianças ${ }^{47}$. Chamou as tropas de Cesareia para matar alguns delegados e entraram no distrito norte de Betesda para dominar a torre Antônia e da área do Templo, porém, não conseguiu seu propósito, pois, os judeus, amotinados, destruíram o pórtico norte e impediram que tivesse acesso à torre Antônia ${ }^{48}$.

Ademais, as acusações dos habitantes de Jerusalém contra Floro conseguiram a obtenção de uma investigação sobre o posto do tribuno. $\mathrm{E}$, quando este foi embora, recomeçaram os motins e desordens, apesar dos esforços de pacificação de Agripa II. As autoridades judaicas, diante da violência contra Roma, pediram ajuda a Floro e Agripa e, quando receberam, ocuparam a colina ocidental. Os revoltosos dominaram o Templo e o monte sudeste. Os romanos se trancaram na fortaleza Antônia. Começada a luta, os insurgentes, depois de ter queimado o palácio dos Asmoneus, a casa do sumo sacerdote e a torre Antônia, cercaram os legionários e os mataram traiçoeiramente, na torre Hípoco, Fasael e Mariane. O legado da Síria, Caio Céstio Galo, apressado com tropas de reforço, incendiou o bairro norte. E, quando ele estava ao alcance da vitória, se retirou de forma inesperada ${ }^{49}$.

Por fim, destaca-se que a revolta se tornou geral, e Vespasiano veio à Palestina em 67, subjugou todo o país, antes de atacar Jerusalém. No ano 69, nomeado imperador, encarregou seu filho Tito para preparar o ataque à cidade ${ }^{50}$. Tito avançou do noroeste, conquistou todos os muros e chegando a cerco mais antigo, onde fez construir aterros. Também a

\footnotetext{
45 Cf. PIMENTEL, 1970, p. 844.

46 Cf. PIMENTEL, 1970, p. 844.

47 Cf. PIMENTEL, 1970, p. 844.

48 Cf. PIMENTEL, 1970, p. 844.

49 Cf. PIMENTEL, 1970, p. 845.

50 Cf. PIMENTEL, 1970, p. 845.
} 
fortaleza Antônia foi sitiada. Um muro de mais de 8 quilômetros de comprimento circundava a cidade e no final, veio a fome, também semeou o massacre, e foi bem-sucedido na conquista do muro norte. O mesmo aconteceu na fortaleza Antônia e os romanos, depois de ter passado a fio de espada os judeus no Templo, saquearam a cidade baixa e colocaram fogo até a piscina de Siloé. A mesma coisa aconteceu a toda a cidade alta, do palácio de Herodes não restou mais que três torres do Templo e somente um muro ${ }^{51}$.

\section{Considerações finais}

Jerusalém, Jerusalém: são hoje todas as cidades, cujo chamado universal à santidade acaba sendo diluído diante da necessidade desenfreada de obtenção e manutenção do poder e do status social. É toda grande ou pequena cidade cuja religiosidade não é geradora de vida, ao contrário, faz com que cada vez mais vidas sejam ceifadas. E, diante dessa constatação, todos os seus habitantes são chamados a contemplarem a Luz da Estrela que é Jesus Cristo. É todo espaço que é chamado para ser a morada de Deus na terra, a ser lugar de salvação, mas o projeto do lucro massacra os mais pobres, abafa a voz de Deus, e modifica a desejo divino de habitação permanente com o seu novo povo. Argumenta-se que assim como a Jerusalém do período de Jesus não soube compreender o plano salvífico universal que foi concretizado em Jesus Cristo, hoje, as cidades e os seus habitantes continuam a não querer compreender a mensagem do Evangelho. Todos são chamados, insistentemente, para superar toda dificuldade e toda forma de egoísmo que impedem os cristãos de viverem realmente o plano salvífico. As "Jerusaléns" de hoje também têm suas quedas já previstas por não saberem corresponder ao vocativo de Deus. Entende-se que todos os membros da Igreja, diante da verdade do Evangelho e da voz do Cristo/Messias, são desafiados a preferirem escutar a voz de Deus e contemplarem a Luz da Estrela. Fugindo assim de outras vozes e pseudoverdades reafirmando mensagens e ideias que não condizem com o verdadeiro ensinamento dos Apóstolos e tão pouco com a Tradição da própria Igreja. Por fim, a Jerusalém de hoje é o lugar, que a imagem da Jerusalém de Jesus, refaz os mesmos passos, os mesmos gestos reproduzem a mesma lógica e mantém o mesmo imaginário de inexpugnável, mas, não conseguem ver sua fragilidade. Assim,

$51 \quad$ Cf. PIMENTEL, 1970, p. 845-846. 
são exortados hoje à verdadeira necessidade de retorno ao seu vocativo primeiro, a viver o plano salvífico universal, sendo sinal de santidade para toda humanidade.

Jesus confirma a desolação sobre Jerusalém e a Casa de Deus que foi predita em Jeremias (Jr 12,7). O abandono da Casa de Deus retoma a Shekinah do antigo Israel, agora de uma forma distinta: antes Deus fazia que as nuvens pairassem sobre a Arca da Aliança e a tenda, agora o próprio Deus quer estar presente na Igreja, e se compromete a estar com esta até a consumação dos tempos. Deus sempre deseja que todos sejam reunidos, o Filho mantém o mesmo desejo do Pai, o mesmo sentimento de reunir os filhos fugitivos e dispersos. A imagem da ternura representada pela ave/galinha que protege os seus filhotes está implícita no "sonho" da verdadeira Jerusalém. Ela apresenta o grande amor e proteção para com os seus filhos todos, sem fazer qualquer tipo de discriminação, por parte de Deus e de Jesus. Essa concretização utópica hoje se efetiva nos cristãos, mas quando se ver uma trupe de seres que se pousam de cristãos, mas, não passam de fariseus, acabam por desvirtuar o plano de Deus para a efetivação da verdadeira Jerusalém. Há, na atualidade, uma verdadeira confusão e atitudes de julgamentos que geram desagregação e isso precisa ser banido definitivamente do bojo de qualquer cidade. Somente assim a Jerusalém se tornará a voltar a ser imagem potente da águia (Ex 19,4; Dt 32,11) que igualmente protege a sua ninhada.

Entende-se que hoje, o lugar que Deus escolheu para ser sua morada se tornou um antro de assassinos violentos, sempre dispostos a eliminar aqueles que falam a verdade diante da realidade caótica que caminha contrária ao projeto de Deus. Os fariseus e escribas denunciados por Jesus não romperam formalmente com Deus, antes se apresentam escrupulosamente apegados à tradição e à Lei mosaica. O grande erro destes está em transformar a religião em um depósito de leis a serem cumpridas, independentes da vontade divina de fazer a misericórdia, a justiça e a fidelidade (Mt 23,23), e serem os sinais da fidelidade ao projeto de Deus, longe da vaidade religiosa e da casuística (Mt 6,1-4).

Por fim, não muito diferente dos tempos de Jesus Cristo, os opositores do messianismo de Jesus, em todos os tempos e lugares, têm todas as oportunidades de escutá-lo e de contemplar a sua Luz. Porém negam lhe escutar (Mt 23,39). A loucura se evidenciará quando chegar o juízo, quando o Servo rejeitado, o Messias, for acolhido com grande glória: "Bendito o que vem em nome do Senhor" (S1 118,26; Mt 21,11; 23,39; 
Lc 13,35; 19,28; Jo 12,13). Chegará o inevitável momento no qual os que se corromperam, desviando a sua conduta religiosa, fazendo-a ser sinal de hipocrisia e de injustiça, passarão pelo crivo do julgamento definitivo de Deus. Os fariseus e os escribas (de ontem e de hoje) com suas falsas seguranças religiosas são chamados à conversão. E com eles todos aqueles que se deixaram contaminar pelo legalismo desprovido de misericórdia. O processo de conversão e esperança possibilitará a vida digna que brota da prática de justiça que é inerente ao ser do discipulado. Somente assim se efetivará a concretização da Jerusalém na qual reina a justiça e a paz.

\section{Referências}

ARMSTRONG, Karen. Jerusalém: uma cidade, três religiões. São Paulo: Companhia das letras, 1996.

BARBAGLIO, Giuseppe; FABRIS, Rinaldo. Os Evangelhos (I) Comentários I. São Paulo: Loyola, 2014.

BÍBLIA DE JERUSALÉM. São Paulo: Paulus, 2004.

BIBLEWORKS project for BibleWorks 10. Versão 10.0.8.755: BibleWorks Copyright, 2017.

CARREZ, Jerusalém. In: BROWN, Colin; COENEN, Lothar. Dicionário Internacional de Teologia do Novo Testamento. 2. ed. São Paulo: Editora Nova Vida, 2004.

CLIFFORD; MURPHY. Gênesis. In: BROWN, Raymond E; FITMEYER, Joseph A.; MURPHY, Roland E. Novo comentário Bíblico São Jerônimo-AntigoTestamento. São Paulo: Paulus, 2007.

FAUSTI, Silvano. Una comunità legge il Vangelo di Matteo. Bologna: EBD, 2001

JEREMIAS, J. Jerusalém no Tempo de Jesus. São Paulo: Paulinas,1963.

LUZ, Ulrich. Vangelo di Matteo. Vol. I-IV. Brescia: Paideia Editrice, 2013.

MAZAR. Città di Gerusalemme. In: ROLLA, Armando. et ali. Enciclopedia della Bibbia. Vol. 2. Torino-Leumann: Elle Di Ci, 1970.

MICHELINI, Giulio. Matteo: Introduzione, traduzione e comento. Torino: Edizioni San Paolo, 2013. 
PIMENTEL. Città di Gerusalemme (história). In: ROLLA, Armando. et ali. Enciclopedia della Bibbia. Vol. 2. Torino-Leumann: Elle Di Ci, 1970. RAMLOT, Teologia sul Gerusalemme. In: ROLLA, Armando. et ali. Enciclopedia della Bibbia. Vol. 2. Torino-Leumann: Elle Di Ci, 1970.

SCHWANTES, Milton. Projetos de Esperança: Meditacão sobre Gênesis 1-11. São Paulo: Paulinas, 2009.

VITÓRIO, Jaldemir. Lendo o Evangelho segundo Mateus: O caminho do discipulado do Reino. São Paulo: Paulus, 2019.

VIVANO. Benedict. O Evangelho Segundo Mateus. In: BROWN, Raymond E; FITMEYER, Joseph A.; MURPHY, Roland E. Novo comentário Bíblico São Jerônimo-Novo Testamento e artigos sistemáticos. São Paulo: Paulus, 2011. 